\title{
O Fluminense e a nostalgia das referências perdidas
}

\section{Leticia Cantarela Matheus}

\section{Resumo}

Este artigo advém de uma pesquisa em andamento sobre o uso que os jornais fazem do passado para legitimarem suas próprias posições nos diferentes sistemas comunicacionais. Ele traz um estudo sobre O Fluminense, jornal centenário de Niterói - RJ, que precisou estabelecer certas estratégias para tentar manter sua posição no mercado local. Uma dessas estratégias foi tentar reconstruir sua própria identidade bem como a de seu público. Ele revela que os jornais não possuem o mesmo significado em qualquer lugar, mas que atendem a diferentes demandas de acordo com cada sociedade. Neste caso, O Fluminense não foi apenas um sinal de modernização, mas justamente um signo de tradição.

\section{Palavras-chave}

Jornalismo. Narrativa. História. Tradição. Identidade.
Leticia Cantarela Matheus | leticia_matheus@yahoo.com.br Doutoranda em Comunicação pela Universidade Federal Fluminense UFF. Bolsista Nota 10 da Faperj.

\section{Introdução}

Este artigo nasceu de um estudo comparativo entre as edições centenárias de três dos mais antigos periódicos em circulação no estado do Rio: Jornal do Commercio (182 anos), $O$ Fluminense (131 anos) e o Jornal do Brasil (118 anos). 0 objetivo era verificar os usos que esses jornais fizeram do passado ao confeccionarem narrativas com pretensão historiográfica. Para este artigo, destacaram-se as particularidades do jornal $O$ Fluminense, sediado em Niterói RJ (a $14 \mathrm{~km}$ da capital). 0 objetivo foi perceber a diversidade de representações possíveis de passado e de seus usos como estratégia de legitimação do jornalismo e, sobretudo, a multiplicidade de funções que as práticas jornalísticas adquirem em diferentes sociedades e em diferentes contextos históricos.

A relação que esse periódico estabeleceu narrativamente com o tempo na ocasião de seu centenário foi atravessada por uma questão particular e que, justamente pela tensão que provocava, fornece dados preciosos: 0 reposicionamento do periódico frente a um lugar 
social que não mais existe. Como este diário usou o passado para manter seu lugar de fala?

Quando ele comemorou seus cem anos (1978), o espaço que lhe conformara por 97 anos havia se tornado oficialmente ausência: 0 antigo estado do Rio de Janeiro. Por outro lado, esse mesmo espaço, na sua dimensão simbólica, permanecia como um fantasma do passado que precisava ser confrontado com um novo espaço político: 0 novo estado do Rio, incorporando então o estado da Guanabara.

0 diário buscava, então, "o povo fluminense", enfim, seu público. É evidente que este público, enquanto conjunto de indivíduos, podia ser 0 mesmo e provavelmente era. Mas seus jogos identitários já não eram os mesmos e ele precisava reelaborar sua inscrição na história bem como seu valor simbólico. 0 próprio tempo político já era outro, a partir da demarcação de um novo ponto zero na cronologia da história local: a fusão da Guanabana, em 1975, formulação de descontinuidade que 0 jornal precisaria rearticular simbolicamente em suas narrativas. Como a edição centenária de $O$ Fluminense pode dar pistas de seu deslocamento como fonte de representação nesse novo espaço social? Que novas relações temporais ela apontava?

\section{Capitalizando o simbólico}

Fundado em maio de 1878 por Prudêncio Luís Ferreira Travassos, $O$ Fluminense não figura em nenhuma das principais obras de história da imprensa no Brasil, tendo sido citado apenas no levantamento de Godofredo Tinoco (1965). De certa forma, sua edição centenária recupera essa "falta de história". A edição é dividida em três produtos impressos distintos, encartados conjuntamente. 0 primeiro é 0 caderno regular, mas que incorpora as comemorações de modo noticioso. Nele, 0 aniversário é transformado em acontecimento público, de caráter coletivo. A edição contém também dois outros cadernos, estes sim, especiais: primeiro, o suplemento em formato standard, composto por oito cadernos, sobre aspectos socioeconômicos e culturais do estado; e, o segundo, um tabloide em cores com a história de $O$ Fluminense.

O jornal dá início a suas comemorações com alguns dias de antecedência, fazendo uma contagem regressiva, indicada na primeira página, e anunciando uma série de eventos pela cidade promovidos pela empresa. No caderno principal, procura envolver a comunidade nos festejos, mobilizando-a. Quatro dias antes (05/05/1978), havia antecipado: "Dia 9 começa um novo século", com a ilustração de uma gráfica antiga. A edição seria a inauguração de um "novo tempo". Mas esse "novo" teria um sentido de renovação, não de ruptura, porque o que o jornal procurou construir narrativamente foi justamente sua "tradicionalidade", como diz Ricoeur (1996). Sua continuidade frente ao passado tornado tradição.

Nas semanas anteriores àquele dia, as chamadas antecipavam as celebrações e o jornal já 
começava a delinear um problema que seria amplamente desenvolvido mais tarde: as identidades de seu público e a sua.

No dia 5 de maio, na página 6 , contava a história de um personagem que encarnava o típico fluminense que seria enfocado exaustivamente na edição centenária. Morador da Engenhoca e natural de São Gonçalo, Antônio Soares Rego, que completara cem anos um mês e um dia antes de $O$ Fluminense, foi perfilado em página inteira, com duas fotografias grandes em close em preto e branco, numa delas, com um fiapo de palha na boca, caracterizando o personagem que encarnaria o "fluminense" procurado pelo jornal: o roceiro. Tipo esse só contrabalançado pelo operário naval e em parte pelo pescador, personagens também representadas pelo jornal.

A tentativa de construir um tipo ideal que encarnasse a identidade regional fica explícita no título da primeira matéria do Caderno "0 homem fluminense", encartado na edição centenária (p. 3): "Em sua terra ele é, antes de tudo, um forte". A referência à famosa frase de Euclides da Cunha acerca dos sertanejos evidencia a intenção do jornal: construir uma identidade regional da mesma forma que Euclides da Cunha procurava fazer ao enaltecer o sertanejo como 0 brasileiro típico, para que jamais nos identificássemos como o "mestiço neurastênico do litoral." (CUNHA, 1991, p. 81) Mas, assim como Euclides da Cunha tinha um "outro" que tentava evitar na formação da identidade nacional, no caso o negro e seus descendentes, também $O$ Fluminense devia ter um "outro" que procurava excluir da formação do ser fluminense. Quem seria ele?

A reportagem sobre seu Antônio começa simulando a fala de um historiador contando que "de 1878 a 1978 muitas coisas aconteceram no Brasil" e as enumera, mas nessa lista não constam apenas fatos da história "oficial", política, mas também outros de natureza essencialmente simbólica, como a alunissagem. 0 historiador, um ser genérico para $O$ Fluminense, poderia dizer que "este é um País de muitos e diferentes séculos..." ( $O$ Fluminense, 05/05/1978, p. 6)

Entre as temporalidades do historiador e as de seu Antônio, O Fluminense se posiciona claramente ao lado do último. É com olhos de testemunha e de quem viveu que ele pretende montar sua autoridade, não com a autoridade de quem "historiografa".

Das três possibilidades da hermenêutica da história de que fala Ricoeur (1996), o Mesmo, o Outro e 0 Análogo, é segundo a analogia que o jornal monta seus argumentos. Ele legitima seu falar pelo poder da experiência que pega emprestado de seu Antônio, exemplo do povo fluminense. Sua experiência lhe confere autoridade para "ter muito o que contar". Portanto, não é somente o jornal que possui capacidade de contar. Ele escolhe, pelo menos nesse momento, um personagem emblemático para encarnar 0 ideal identitário do povo fluminense. 
Não se trata apenas do problema de como $O$

Fluminense representou "o fluminense", mas que dessa articulação dependia sua localização no mercado linguístico (BOURDIEU, 2008). Não apenas o sentido de seu discurso estaria marcado por sua posição nas estruturas do mercado comunicacional, mas também seu valor simbólico, frente a outros periódicos, diretamente, e frente a outras formas de representação social, de modo mais genérico.

Ele precisava traçar uma lógica própria, de modo a captar competências particulares para se fazer entender e para adquirir relevância social dentre tantas outras de fontes discursivas no cotidiano. Como o jornal traça essa lógica? Definindo sua identidade narrativa (RICOEUR, 1991), a partir de uma dupla operação: desenvolvendo um modo próprio de narrar e uma identidade construída na narrativa.

0 que se entende por mercado comunicacional? Não se trata, apenas, de mercado no sentido estreito, comercial: do quanto $O$ Fluminense ganhou ou perdeu de leitores, de anunciantes, de assinantes, mas de um ganho simbólico. Segundo Bourdieu (2008), o valor de um discurso, ou melhor, sua autoridade, não advém de características imanentes a ele, como se possuísse uma força ilocutória, mas das relações de força travadas concretamente por seus locutores. Ou seja, o discurso possui um valor relativo, dependendo da situação em que é enunciado e dos atores envolvidos no circuito enunciação-apropriação. E, ainda que a riqueza material dos locutores seja um dos elementos de força nessas disputas, ela não é conversível em lucro simbólico de forma óbvia, linear e necessária. Nem 0 contrário é determinado. 0 lucro simbólico pode ou não ser convertido em riqueza material, embora seja fator importante para a definição das regras dessas trocas.

Permitindo-se traduzir mercado linguístico por mercado comunicacional, 0 valor de uma forma específica de comunicação - o jornalismo - só é estabelecido na relação com todo o mercado (ou sistema comunicacional, como preferimos). Se o valor de troca de uma mercadoria só existe $n a$ troca e por causa da troca, como diz Marx (2008), e se Bourdieu (2008) incorpora esse vocabulário econômico para explicar sociologicamente as interações comunicacionais, então o valor de $O$ Fluminense e do jornalismo em geral só é estabelecido em relação a todo 0 conjunto de práticas comunicacionais de uma sociedade. Seu valor (autoridade/ legitimidade) não é dado; é resultado parcial de interações sociais mais amplas.

O Fluminense precisava usar aquela edição que estava sendo preparada para reivindicar certa identidade que possibilitasse ao leitor reconhecê-lo e inseri-lo em certa posição nas hierarquias do sistema comunicacional. $\mathrm{Ou}$ seja, precisava reivindicar a manutenção de sua autoridade, agora frente a novas posições ocupadas por outros atores nesse sistema. Afinal, os periódicos sediados na cidade do Rio 
haviam deixado de ser jornais da capital federal em 1960, deixaram de ser jornais do estado da Guanabara em 1975, passaram a ser jornais da capital do estado do Rio e $O$ Fluminense deixou de ser um jornal de capital. Daí a ansiedade por reposicionamentos e a evocação nostálgica do passado na forma de tradição.

\section{Entre a enxada e as letras: as fronteiras de um público}

A antecipação do problema identitário numa edição regular anterior à de aniversário só reforça a tese de sua importância nas comemorações. Isso fica patente nos anúncios produzidos pelas Câmaras e Prefeituras de municípios do estado que, ao parabenizar O Fluminense nos anúncios na edição centenária, reafirmam sempre que se trata do jornal $d o$ (com artigo definido) estado do Rio. Ou seja, com sentido de único. Assim como seu valor como locus de tradição.

0 estado do Rio havia acabado da forma como era. A capital fora transferida para a cidade do Rio, antiga sede do estado da Guanabara. Com tantos importantes periódicos sediados na nova capital, como O Fluminense se posicionaria? Quem seriam seus anunciantes? E as publicações oficiais de governo, com suas respectivas verbas, para quem iriam? Como ficaria o diálogo com as autoridades de governo, a partir de então mais distantes da esfera de influência de $O$ Fluminense? Como ele ficaria diante dessa nova configuração mercadológica e simbólica?
0 mapa que o próprio jornal publica na primeira página do Caderno "As regiões" não possui a indicação da localização de Niterói. Isso é bastante significativo do quadro com que 0 jornal teria que lidar. Há um incômodo silêncio. Tentando se manter como "o" jornal do estado, ele perdia espaço, no Leste fluminense, para outros periódicos como O DIA, O Globo e Jornal do Brasil.

Tendo como primeira página, colorida, um galo formado a partir das letras do nome "O Flu", num fundo montanhoso com o sol raiando em grossos feixes amarelos espalhados por toda a página, o suplemento especial teve como título "O Produto Fluminense" e foi editado em oito cadernos de 12 páginas cada. Os cadernos foram divididos tematicamente.

0 grau de investimento que demandou este suplemento é evidenciado pela quantidade de conteúdo elaborado, pelos textos e fotografias, indicando que pelo menos uma equipe do jornal foi destacada para passar um bom tempo viajando pelo estado produzindo esse material. Por isso, "0 Produto Fluminense" é o que mais caracteriza as comemorações, ou seja, é o material editorial mais excepcional em relação ao cotidiano da produção jornalística, com grande potencial para a capitalização simbólica e financeira da empresa, já que é repleto de anúncios.

0 que fez os jornalistas e dirigentes de $O$ Fluminense sentirem a necessidade de produzir um suplemento tão grande e trabalhoso para os 
padrões daquele jornal? Por que não ficar apenas com o tabloide que contava a história do jornal? E por que separar a história do estado da história do próprio periódico?

A impressão que se tem é que o suplemento, embora tenha sido apresentado como material de pesquisa, tratou sobretudo de conjunturas recentes, entendidas como provisórias. Ele falava de uma realidade da qual os anunciantes faziam parte e ajudavam a alterar com suas ações.

0 suplemento se assemelha a uma grande revista, traçando um panorama do estado. Trata do presente e do futuro. Não há destaque para articulações acerca de "tempos idos".

(BARB0SA, 2008) A noção mais forte de passado que se tem é enquanto tradição, e tradição não é "tempo ido", mas continuidade, estabilidade. É uma espécie de tempo eternamente presente, o "sempre foi assim". Ou seja, trata-se de uma força conservadora.

Ricoeur (1996) decompõe tradição em três articulações conceituais: tradicionalidade, "tradições" e tradição. A primeira, tradicionalidade, diz respeito à forma de encadeamento da sucessão histórica, à mediação das interpretações das heranças no transcurso do tempo. A segunda, tradições, apresenta-se como conjunto de representações já realizadas, "coisas já ditas" (p. 380), transmitidas por cadeias transgeracionais de interpretações e reinterpretações (o ser afetado pela história). Esta, a nosso ver, confunde-se com a própria historicidade. Trata-se daquilo que já estava feito quando nascemos. É a mimese I, préfiguração do mundo. Enquanto a mimese III (refiguração do mundo) é a ação de recepção, inclusive do passado, e a mimese II, a mediação entre um e outro, "os textos" que produzimos, nosso percurso entre presente e passado. Por último, segundo a terceira concepção, tradição surge como instância de legitimação que designa uma pretensão de verdade, antes que qualquer gesto crítico.

É verdade que $O$ Fluminense não problematiza tradição com tal grau de complexidade e crítica, mas as três articulações estão lá. Tradicionalidade, como filiação a um passado imaginado por encadeamento num tempo linear. Tradições, como conteúdo, como um conjunto herdado, ainda que o jornal não explicite em nenhum momento sobre que tradições está falando. E, sobretudo, conforme a terceira concepção, como instância legitimadora, ainda que difusa, imprecisa.

Segundo Hobsbawm (2006), tradição funciona com força de coesão social (identidade) ao usarmos o passado como continuidade no presente. Em que passado se vai buscar isso e 0 grau de intencionalidade racional com que se realiza essa operação varia de acordo com 0 objeto de análise. Mas basicamente 0 que define 0 uso do passado como tradição ou história é o grau de sua indefinição, de generalidade. Ou seja, embora olhar para 0 
passado seja sempre produzir uma narrativa a partir de uma perspectiva (necessariamente do presente), afirmar que o passado é história ou tradição vai depender do grau de precisão das considerações embutidas nessa narrativa. Por que $O$ Fluminense não fez "a história do estado do Rio"? Preferiu destacar personagens e valores atribuídos ao universo tradicional. Optou, pelo menos no suplemento, por não celebrar datas e antepassados. Comemorou algo difuso e impreciso traduzido como tradição.

É claro que a tradição é também um modo de interpretação da historicidade. 0 que se destaca é que não existem essências próprias de tradição, história e memória. Apenas que são abordagens diferenciadas de um tempo social entendido como tendo passado, isto é, diferentes modos de representação e de consciência desse passado.

Ainda segundo Hobsbawm (ibidem), nas sociedades contemporâneas, a elaboração e evocação de tradições (ao que ele chama invenção) seriam acentuadas em períodos de instabilidade, de rápidas mudanças, e se refeririam a um passado impreciso, justamente devido à esterilidade de suas referências para novas estruturas, ou como preferimos, pelo significado desfavorável que tal passado representaria para certo grupo social num determinado momento se esse grupo não fosse capaz de rearticulá-lo rapidamente, de modo a potencializar seus lucros simbólicos.

No caso de $O$ Fluminense, o jornal se valeu de uma noção de tradição para produzir novos laços identitários e reafirmar antigos. Foi uma forma de manutenção de antigas lealdades e de reafirmação de sua autoridade local.

No "Produto Fluminense", as narrativas apresentam e trabalham a tensão entre tradição e modernidade, cidade e campo, em torno tanto do problema do êxodo rural quanto da expansão dos meios de comunicação, mas sempre tendo como pano de fundo, ou insinuando, um problema identitário que tocava na recente fusão do estado da Guanabara (cidade do Rio) com o antigo estado do Rio. Portanto, o suplemento encerra essa tripla tensão entre tradição/modernidade, campo/ cidade e as identidades fluminenses.

Frequentemente se caracteriza o campo como o lugar da tradição e a cidade como o lugar da modernidade. Essa dicotomia reproduz, por sua vez, certas atribuições dadas à tradição e à modernidade no senso comum. A tradição seria conservadora e modernidade progressista, no sentido de mudança. Esses adjetivos são carregados de juízos de valor, dependendo das posições políticas e intelectuais de quem que os utiliza. Mas concretamente esses significados não são estáveis e tanto um adjetivo quanto outro assumem formas catalisadoras de múltiplos significados em situações concretas de ação.

Por exemplo, enquanto Mayer (1987) relata que a persistência das forças tradicionais do antigo regime europeu e mesmo do feudalismo em pleno século XX foram a principal razão das duas grandes guerras; por outro lado, Williams (1989) 
mostra que as forças da tradição podem tanto ser fonte de resistência quanto de integração criativa em novos contextos. Há uma série de sentimentos estruturados, para usar o conceito de Williams, em torno do modelo de oposição campo/ cidade: estagnação e progresso, ilusão e racionalidade, ignorância e instrução, trevas e luzes, inocência e degenerescência etc. $0 u$ seja, ainda que não haja em hipótese alguma uma essência urbana e uma essência rural, sendo industrial ou não, agrária, florestal ou não, cosmopolita ou não, cidades e campos acabam tendo cristalizados em torno de si alguns sentimentos. Alguns deles são muito claros no jornal.

A falta de saúde e educação aparece nesta edição quase que como características naturais, inerentes ao campo, tanto que são associadas à vergonha que 0 homem do interior poderia ter. Ela sintetiza toda a tensão tradição/ modernidade, campo/ cidade. 0 interior, como campo, é associado a condições rurais e isso seria vergonhoso. A cidade, onde o jornal explicitamente se insere, é o lugar da instrução que deve ser levada ao homem do campo. Assim, seu papel iluminador é intimamente vinculado ao papel iluminador do intelectual.

Chama a atenção a total coincidência dos papéis do intelectual e do jornalista neste caso. É claro que todos os trabalhadores, a rigor, segundo Gramsci (1995), são intelectuais, mas nem todas as pessoas desempenham funções de intelectuais, como categoria profissional particular. Sobretudo no Brasil, onde o jornalismo está tão intimamente vinculado à esfera literária, segundo Barbosa (1996), esta marca de "intelectualidade" se torna fator altamente distintivo no meio profissional e nas expectativas do público, com a suposição de uma função de esclarecer e educar as massas, de tutelá-las. Tal concepção combina perfeitamente com diversas "linhagens" conservadoras do pensamento social no Brasil.

Ainda de acordo com O Fluminense, o jornalista assumiria a função de ser responsável por incutir no interiorano 0 orgulho de seus modos de vida, como se ele já não o tivesse e como se a realidade que 0 faz migrar para os centros urbanos não existisse. Ao mesmo tempo, o jornalista não se confunde com esse arquétipo interiorano. Ele permanece 0 intelectual, vetor de modernidade. É aquilo que "estraga" a cultura, mas também aquilo capaz de a "preservar". Ou seja, a vida interiorana seria tutelada por $O$ Fluminense na forma de tradição. Ele acredita e espera ter um enorme poder sobre 0 universo do qual fala. Ainda que demonstrando preocupação com sua responsabilidade, é dessa forma mesmo que constrói seu poder. Bourdieu (2008) fala que um mercado linguístico funciona como sistema de objetivação de relações desiguais de poder do qual ele mesmo é produto.

0 problema da cultura continua em $O$ Fluminense, como na p. 4, numa fotografia no 
alto de página: uma casa de campo, com gente na porta e outras pessoas por perto nos seus afazeres cotidianos. No canto inferior direito da mesma página, outra fotografia, desta vez de um pescador costurando rede, com a legenda: "0 atavismo mantém constante 0 modo de 0 pescador garantir seu sustento e o da família." Ora, "manter constante" um modo de sobrevivência é manter a tradição. 0 jornal explora nessa reportagem todo um universo bucólico com o qual pretende representar o interior do estado. 0 texto tem ainda um olho que diz: "A cidade corrompe sua cultura". E o título da reportagem é "Viver, trabalhar e morar". Nela, são narradas as relações tradicionais de trabalho, de habitação e de se comportar do homem interiorano que $O$ Fluminense se dedica a descrever. A página 6 trata do mesmo tema: "Como se manter na terra", entre inúmeros exemplos. E a cultura popular é definida por sua condição de espontaneidade.

Ao mesmo tempo, num tom enaltecedor das vantagens de se ser "interiorano", o jornal relata uma série de situações em que "ser do campo" é melhor que "ser da cidade". Ele celebra esse modo de vida idealizado "do campo-tradicional". O Fluminense diz que o morador de Trajano de Moraes se vangloria de "passar a manta" no homem da cidade; que prevalece em Santo Amaro de Campos o status do homem a cavalo no que concerne à sedução feminina; entre outros exemplos. E diz que embora não seja possível fazer um prognóstico sobre a permanência dos valores do campo (o que ele faz o tempo todo), conclui que "preservar a cultura é reter o homem no seu meio-ambiente".

Mais uma vez, há a tensão entre a tradição e a mudança, havendo, na compreensão do jornal, a necessidade de 0 homem do interior permanecer o mesmo, valorizando a tradição: "seus valores" e "festas herdadas dos ancestrais". Assim como o turismo, a mídia aparece como desarticuladora de antigos laços tradicionais, ou seja, como vetor da modernidade. Vê-se nitidamente aí 0 lugar do campo como imagem daquilo que é tradicional enquanto conservador. Já os meios de comunicação aparecem como elementos desintegradores da cultura tradicional, entendida como algo estável.

Ao mesmo tempo, O Fluminense não se questiona como sendo também mídia, direcionando à televisão a responsabilidade por levar para o campo degenerescência típica da cidade. Assim, seu lugar se torna ambíguo. Afinal, ele se encontraria de que lado no par campo/ cidade? Essa ambigüidade pode ser encontrada também nos anúncios publicitários, tais como o do refrigerante Mineirinho que, assim como o jornal, é apresentado como símbolo da tradição fluminense.

0 modelo campo/ cidade reproduz uma estrutura de sentimento que se atualiza, segundo Williams (ibidem), "no sistema que agora denominamos imperialismo" (p. 375). Ele seria 0 antecessor primário do esquema centro/ periferia, Norte/ Sul, desenvolvido/ subdesenvolvido, como 
descreve também Mignolo (2003). Na prática, não importa se 0 campo a que nos referimos é interior mesmo ou litoral, se é agrário ou não, podendo ser até mesmo industrial, ou se a cidade em questão é uma corte, se é uma metrópole ou não. 0 que está em jogo é muito mais uma classificação hierárquica. No nível local do Rio de Janeiro e no nível mercadológico, para $O$ Fluminense, essa articulação precisou mudar após a fusão dos antigos estados. Trata-se de um jornal periférico em relação ao centro ou central na periferia?

\section{Fundindo espaços imaginados}

A fusão da Guanabara em 1975, durante 0 governo Ernesto Geisel e no ano de inauguração da ponte na Baía de Guanabara, aparece em dois momentos explícitos nesse suplemento e de uma terceira maneira mais implícita. Os dois primeiros dizem respeito aos cadernos: "As regiões" e "Administração". A terceira forma é difusa por todo o suplemento.

No caderno 8 - "Administração" - 0 secretário estadual de Indústria e Comércio, Marcel Hasslocher, assina artigo com o título "Fusão garantiu ao Estado do Rio melhores condições para progredir". 0 caderno "As regiões" tem como manchete: "0 Estado do Rio tem um novo mapa. Veja onde estão seus melhores frutos". Abaixo, 0 jornal publica um mapa dividido por "Programas de Ação Regional", informando sobre as vocações das diferentes regiões do Rio, a partir da recente reconfiguração. Ainda abaixo do mapa, algumas fotografias com as legendas: "Rio - metrô"; "Barra
Mansa/ Volta Redonda - aço"; "Macaé - turismo de praia"; "Friburgo - turismo de serra"; "Campos - açúcar e petróleo".

Seguindo o raciocínio de Bourdieu (2004), assim como a classificação é um exercício de poder, ao se nomearem as coisas, a divisão imaginária dos territórios também constitui um modo de classificação, e, assim, de exercício de autoridade sobre eles. Portanto, já se tem dois "objetos" de apropriação pela nomeação: 0 espaço e 0 tempo, afinal, o que é operação historiográfica (CERTEAU, 2007) senão uma forma de classificação das temporalidades?

Classificar por região é propor uma nomeação que produz efeitos sociais práticos. Não que uma região coincida com espaços físicos. Ela é antes de tudo uma representação mental, um "objeto de percepção e apreciação, de conhecimento e reconhecimento em que os agentes investem seus interesses e pressupostos." Por outro lado, essa representação espacial não se resume a uma existência na mente. Ela é também "objeto de representação objetal em coisas, atos, estratégias de manipulação simbólica que têm em vista determinar a representação mental que os outros podem ter destas propriedades e dos seus portadores." 0 que está em jogo é o poder de impor uma visão de mundo através de certos critérios de divisão do espaço e dos grupos (BOURDIEU, 2004, p. 112-113). Critérios esses que o jornal procura definir para potencializar seu poder de determinar as regras 
de formação das leis dos preços simbólicos. Onde há continuidade e descontinuidade territorial e simbólica? Onde está Niterói? Onde está a cidade do Rio e onde está o novo estado do Rio nas representações de $O$ Fluminense?

0 jornal apresenta "as sedes das regiões", de acordo com o que ele chama de "Programas de Ação". Entre elas, há lugar para o Rio, pólo metropolitano; para Friburgo, representando a Região Serrana; Campos, representando a Região Norte; Macaé, pelas Baixadas Litorâneas; e Volta Redonda, pela Região do Médio Paraíba. São, portanto, seis regiões ao todo, segundo a divisão ideal apresentada por $O$ Fluminense, excluindo Niterói, sua cidade sede, de qualquer função nessa nova configuração geopolítica. Estaria Niterói na esfera do campo ou da cidade?

Estavam em jogo não somente ressentimentos pela perda de um lugar político especial, mas também um orgulho compensatório a partir da invenção de uma tradição regional. Ou seja, estar no centro ou na periferia não é algo menor no mercado linguístico. É uma questão de perspectiva de jogo, como diz Bourdieu. Perspectiva essa que define lugares de fala e, consequentemente, graus diferenciados de poder no mercado comunicacional. "As leis dos mercados de bens simbólicos não são os da comunicação indefinida entre sujeitos universais" (op. cit., p. 129-132). Esses sujeitos têm lugares particulares, tanto do ponto de vista simbólico quanto do ponto de vista territorial que rearticula o simbólico.
Ocupar certos lugares é obter maior ou menor autonomia na produção de representações do mundo social que o favoreçam, controlando mais ou menos as leis de formação e regulação de preços nesse mercado comunicacional. Não se pretende afirmar com isso que $O$ Fluminense ocupasse efetivamente um lugar mais relevante antes da fusão. 0 que se analisou é que 0 apelo à tradição na construção da identidade do jornal pós-fusão sugere que houvesse esse sentimento naquele momento.

0 que é mais significativo é que não há nenhuma reportagem referente a Niterói. Tem-se apenas ufanismos referentes ao antigo estado do Rio. Dentro do caderno, a página 2 é dedicada à capital com o título "0 Rio de Janeiro continua lindo?", tendo como subtítulo: "A Capital que quer viver melhor". A reportagem é otimista, tratando a importância estratégica do metrô, entre outros aspectos estruturais. A página é repleta de fotografias, entre elas, 0 tradicional par de nádegas em direção ao mar. A Baixada Fluminense recebe tratamento pejorativo, única área tratada desta forma. Ela é retratada na página 3 do mesmo caderno com o título "Baixada Fluminense, região irritada que desafia o Estado".

A terceira forma por meio da qual a fusão é problematizada requer interpretação mais detalhada. Ela está em toda parte - das reportagens à publicidade - e se refere ao problema das identidades do homem fluminense e do estado. 
No que concerne às reportagens, há pelo menos cinco importantes momentos em que a questão da identidade do fluminense e conseqüentemente do público do jornal é tratada, sempre articulada em função da relação entre campo e cidade. No Caderno 4, dedicado à "Indústria", encontrase na página 12 a descrição do "Operári Fluminense, 1978 (esse ilustre desconhecido)". Com esse título, a reportagem procura mapear as características socioeconômicas e culturais desses profissionais, representantes da identidade fluminense, desta vez tratando os personagens urbanos.

Acompanhado de uma fotografia de operários da indústria naval em cima de algo como um cais ou plataforma, vistos em grupo e de baixo para cima, $o$ texto estabelece claramente a sobreposição entre o ideário do operário fluminense e essa categoria profissional representante do lado Leste da Baía de Guanabara, ou seja, da área de influência do jornal. O Fluminense admite inclusive que os operários navais não são sequer maioria no estado. Mesmo assim opta por estabelecer, de novo, uma relação de exemplaridade.

A reportagem segue com uma pesquisa salarial e 0 texto é entremeado por uma entrevista com o operário naval Adebaldo Fiúza. Soldador profissional há 12 anos, Adebaldo não se considerava um bom soldador, já que acreditava, modestamente, serem necessários muitos anos de experiência para isso. Seus sonhos eram terminar a casa em Duque de Caxias e comprar um Fusca ano 1973. Desse modo, assim como no caso de seu Antônio, O Fluminense articula o valor informativo da exemplaridade em vez de fornecer panoramas genéricos, construindo, portanto, um modo próprio de narrar. 0 texto continua com Adebaldo enumerando as vantagens da mão-deobra especializada, o que pode ser um indício de uma discursividade corrente na época, entre outros aspectos culturais e econômicos de então.

Adebaldo e seu Antônio são, portanto, personagens que integram a configuração narrativa desenvolvida por $O$ Fluminense acerca de seu público. Público aqui entendido de maneira ampla. Adebaldo e seu Antônio podiam não ser leitores de $O$ Fluminense diretamente. Seu Antônio era inclusive analfabeto. Mas eles eram público na medida em que viviam num espaço social impactado pelas mensagens de $O$ Fluminense, num sistema de comunicação mais amplo (DARNTON, 1990). Eram leitores, mesmo que de segunda ou terceira natureza (BARBOSA, 2008), já que sabiam da existência do jornal e até negociavam com ele - deram entrevista, deixaram-se fotografar e até negociaram a pose -, sabiam o que significava aparecer no jornal. Enfim, compartilhavam com um grupo mais amplo o significado do jornal e do jornalismo. Ainda que com apropriações as mais diversas, conferiram a $O$ Fluminense legitimidade e a ele emprestaram suas biografias para a construção de sua identidade. Assim, Adebaldo e Antônio encarnaram os dois polos da oposição conflituosa 
para O Fluminense campo/ cidade, lavrador/ operário, tradição/ modernidade.

Assim como a descrição de Euclides da Cunha, que mescla a relação do homem com a terra, no auge do naturalismo que tanto marcou a construção do jornalismo, também a articulação de $O$ Fluminense se completa pelo meio ambiente e os aspectos socioeconômicos.

\section{No Caderno 3, "Agropecuária", questiona na} página 4 "Por que o produtor é tão pobre?" e responde com a tese da fragmentação da terra em pequenas propriedades, ou seja, indicando 0 agronegócio como solução para o problema. E ainda condena, de certa forma, o pequeno produtor, o que não deixa de ser uma contradição em função dos personagens que o jornal pretende retratar. No mesmo caderno, desta vez na página 12 , lança 0 olhar mais acentuadamente para 0 futuro, imaginando que os satélites salvariam 0 mundo da fome, pois estimariam as safras, pondo fim "às expeculações $[s i c]$ que prejudicam 0 mercado mundial de cereais".

No Caderno 7, "Turismo", veem-se as principais descrições do estado. "Do Rio ao Norte-Flu, tudo é atração", diz o título da primeira página. "Em Parati, um mergulho no tempo" (p. 4); na página 2, a pesca em São Gonçalo e Niterói; as "Praias do sertão, uma boa" (p. 7), sobre São João da Barra, os minerais radioativos que curam em Guaxindiba, entre outras atrações. Ao lançar seu olhar para 0 estado e descrevê-lo, o jornal procura traçar sua marca para a construção de sua identidade. Mas nenhum espaço deste suplemento explicita tanto a construção dessa identidade fluminense quanto o Caderno 1 , não por acaso com o título "0 homem fluminense".

A primeira página do Caderno 1, "0 homem fluminense", traz cinco fotografias significativas. São quatro fotos menores de moradores do interior, parecendo lavradores, e uma maior, ocupando quase toda a metade superior da página em que se tem 0 gado em primeiro plano. As patas dos bois funcionam como moldura para a fotografia e se vê, ao fundo, de longe, dezenas de trabalhadores do campo andando, vindo em direção ao primeiro plano. Não se sabe se indo ou voltando do trabalho.

0 texto, numa coluna do lado esquerdo, diagnostica o principal problema do campo: o êxodo. Neste momento, $O$ Fluminense retoma as referências ao trabalho dos meios de comunicação como "elemento de desagregação" do "homem interiorano, só não pior que êxodo. De novo, o jornal se apresenta como fator de modernidade que ameaça desagregar antigos laços tradicionais.

\section{Considerações finais}

Tentou-se mostrar neste artigo que o passado pode ser também usado de modo difuso pelo jornal, transformado em tradição, segundo os interesses que marcam o momento presente. O Fluminense precisou articular seu lugar no sistema comunicacional da sociedade em que 
estava inserido, apenas três anos depois da fusão dos estados do Rio e da Guanabara, conformando um novo espaço político. Essa nova configuração afetava o mercado linguístico de tal forma que fez com que o jornal realizasse um grande investimento logístico para produzir sua edição centenária, marcando sua analogia a valores tradicionais que, talvez, fossem interpretados naquele momento como ameaçados. Sua comemoração foi oportunidade de inventar sua tradição. Analisaram-se algumas estratégias de auto-legitimação empreendidas por $O$ Fluminense. Parte dessa autoridade adveio do passado, articulado na forma narrativa de tradição.

\section{Referências}

BARBOSA, Marialva C. Imprensa, poder e público (Os diários do Rio de Janeiro - 1880-1920). 1996. Tese (Doutorado em História) - Universidade Federal Fluminense, Niterói,1996.

BARBOSA, Marialva. Reflexões sobre a imprensa no Brasil de 1808. Estudos em Jornalismo e Mídia, Florianópolis, ano V, n. 2, p. 91-109. jul.-dez. 2008. BOURDIEU, Pierre. A economia das trocas lingüísticas. São Paulo: Edusp, 2008.

A identidade e a representação: elementos para uma reflexão crítica sobre a ideia de região." In: o poder simbólico. Rio de Janeiro: Bertrand Brasil, 2004. p. 107-132.

CERTEAU, Michel. A escrita da história. Rio de Janeiro: Forense Universitária, 2007.

CUNHA, Euclides da. 0s sertões. Campanha de Canudos. Rio de Janeiro: Francisco Alves, 1991.
DARNTON, Robert. 0 beijo de Lamourette: mídia, cultura e revolução. São Paulo: Companhia das Letras, 1990.

GRAMSCI, Antonio. 0s intelectuais e a organização da cultura. 9.ed. Rio de Janeiro: Civlização Brasileira, 1995.

HOBSBAWM, Eric; RANGER, Terence. A invenção das tradições. 4.ed. São Paulo: Paz e Terra, 2006.

MARX, Karl. 0 capital: crítica da economia política. Vol. 1. Rio de Janeiro: Civilização Brasileira, 2008.

MAYER, Arno. A força da tradição: a persistência do Antigo Regime. 1848-1914. 2.ed. São Paulo: Companhia das Letras, 1987.

MIGNOLO, Walter. Histórias locais / projetos globais: colonialidade, saberes subalternos e pensamento liminar. Belo Horizonte: UFMG, 2003.

RICOEUR, Paul. Tempo e narrativa, tomo III. Campinas: Papirus, 1996.

TINOCO, Godofredo. Imprensa fluminense: 1826-1965. Rio de Janeiro: São José, 1995.

WILLIAMS, Raymond. 0 campo e a cidade: na história e na literatura. São Paulo: Companhia das Letras, 1989. 


\section{Fluminense and the} nostalgia of lost references

\section{Fluminense y la nostalgia de las referencias perdidas}

\section{Abstract}

This article is derived from an ongoing research about how the newspapers use the past to legitimate their own positions in different communicational systems. It brings a study on "O Fluminense", a centenarian newspaper from Niterói - RJ, that had to establish some strategies to try to keep its position in local marketplace. One of these strategies was trying to rebuild its own identity as well as of its public. It reveals that newspapers do not have the same meaning everywhere, but they respond to each society's different demands. In this case, $O$ Fluminense was not only a sign of modernization, but precisely a sign of tradition.

\section{Keywords}

Journalism. Narrative. History. Tradition. Identity.

\section{Resumen}

Este artículo proviene de un estudio en curso sobre el uso que los periódicos hacen del pasado para legitimar sus propias posiciones en los diferentes sistemas de comunicación. Él trae un estudio de $O$ Fluminense, un periódico centenario de Niterói - RJ, que necesita establecer algunas estrategias para tratar de mantener su posición en el mercado local. Una de estas estrategias es intentar reconstruir su propia identidad y la de su público. Él muestra que los periódicos no tienen el mismo significado en cualquier lugar, pero satisfacen a diferentes exigencias de acuerdo con las diferentes sociedades. En este caso, O Fluminense no era sólo un signo de modernización, sino un signo de tradición.

\section{Palabras clave}

Periodismo. Narrativa. Historia. Tradición. Identidad. 


\section{Expediente}

A revista E-Compós é a publicação científica em formato eletrônico da Associação Nacional dos Programas de Pós-Graduação em Comunicação (Compós). Lançada em 2004, tem como principal finalidade difundir a produção acadêmica de pesquisadores da área de Comunicação, inseridos em instituições do Brasil e do exterior.
E-COMPÓS I www.e-compos.org.br I E-ISSN 1808-2599

Revista da Associação Nacional dos Programas de Pós-Graduação em Comunicação. Brasília, v.12, n.2, maio/ago. 2009

A identificação das edições, a partir de 2008 passa a ser volume anual com três números.

\section{CONSELHO EDITORIAL}

\section{Afonso Albuquerque}

Universidade Federal Fluminense, Brasil

Alberto Carlos Augusto Klein

Universidade Estadual de Londrina, Brasi

Alex Fernando Teixeira Primo

Universidade Federal do Rio Grande do Sul, Brasi

\section{Alfredo Vizeu}

Universidade Federal de Pernambuco, Brasil

Ana Carolina Damboriarena Escosteguy

Pontifícia Universidade Católica do Rio Grande do Sul, Bras

Ana Silvia Lopes Davi Médola

Universidade Estadual Paulista, Brasil

André Luiz Martins Lemos

Universidade Federal da Bahia, Brasil

Ângela Freire Prysthon

Universidade Federal de Pernambuco, Brasil

Antônio Fausto Neto

Universidade do Vale do Rio dos Sinos, Brasil

Antonio Carlos Hohlfeldt

Pontifícia Universidade Católica do Rio Grande do Sul, Brasil

Arlindo Ribeiro Machado

Universidade de São Paulo, Brasil

César Geraldo Guimarães

Universidade Federal de Minas Gerais, Brasil

Cristiane Freitas Gutfreind

Pontifícia Universidade Católica do Rio Grande do Sul, Brasil

Denilson Lopes

Universidade Federal do Rio de Janeiro, Brasil

Eduardo Peñuela Cañizal

Universidade Paulista, Brasi

Erick Felinto de Oliveira

Universidade do Estado do Rio de Janeiro, Brasil

Francisco Menezes Martins

Universidade Tuiuti do Paraná, Brasil

Gelson Santana

Universidade Anhembi/Morumbi, Brasi

Hector Ospina

Universidad de Manizales, Colômbia

leda Tucherman

Universidade Federal do Rio de Janeiro, Brasil

Itania Maria Mota Gomes

Universidade Federal da Bahia, Brasil

Janice Caiafa

Universidade Federal do Rio de Janeiro, Brasil

Jeder Silveira Janotti Junior

Universidade Federal da Bahia, Brasil

\section{João Freire Filho}

Universidade Federal do Rio de Janeiro, Brasil

John DH Downing

University of Texas at Austin, Estados Unidos

José Luiz Aidar Prado

Pontifícia Universidade Católica de São Paulo, Brasil

José Luiz Warren Jardim Gomes Braga

Universidade do Vale do Rio dos Sinos, Brasil

Juremir Machado da Silva

Pontifícia Universidade Católica do Rio Grande do Sul, Brasil

Lorraine Leu

University of Bristol, Grã-Bretanha

Luiz Claudio Martino

Universidade de Brasília, Brasil

Maria Immacolata Vassallo de Lopes

Universidade de São Paulo, Brasil

Maria Lucia Santaella

Pontifícia Universidade Católica de São Paulo, Brasil

Mauro Pereira Porto

Tulane University, Estados Unidos

Muniz Sodre de Araujo Cabral

Universidade Federal do Rio de Janeiro, Brasil

Nilda Aparecida Jacks

Universidade Federal do Rio Grande do Sul, Brasil

Paulo Roberto Gibaldi Vaz

Universidade Federal do Rio de Janeiro, Brasil

Renato Cordeiro Gomes

Pontifícia Universidade Católica do Rio de Janeiro, Brasil

Ronaldo George Hela

Universidade do Estado do Rio de Janeiro, Brasil

Rosana de Lima Soares

Universidade de São Paulo, Brasil

Rossana Reguillo

Instituto Tecnológico y de Estudios Superiores do Occidente, México

Rousiley Celi Moreira Maia

Universidade Federal de Minas Gerais, Brasil

Sebastião Carlos de Morais Squirra

Universidade Metodista de São Paulo, Brasil

Simone Maria Andrade Pereira de Sá

Universidade Federal Fluminense, Brasil

Suzete Venturelli

Universidade de Brasília, Brasil

Valério Cruz Brittos

Universidade do Vale do Rio dos Sinos, Brasil

Veneza Mayora Ronsini

Universidade Federal de Santa Maria, Brasil

Vera Regina Veiga França

Universidade Federal de Minas Gerais, Brasil
COMISSÃO EDITORIAL

Ana Gruszynski I Universidade Federal do Rio Grande do Sul, Brasil Felipe da Costa Trotta I Universidade Federal de Pernambuco, Brasil Rose Melo Rocha I Escola Superior de Propaganda e Marketing, Brasil

\section{CONSULTORES AD HOC}

Aníbal Francisco Alves Bragança I Universidade Federal Fluminense, Brasil Benjamim Picado I Universidade Federal da Bahia, Brasil

Carlos Eduardo Franciscato I Universidade Federal de Sergipe, Brasi

Christa Liselote Berger I Universidade Vale do Rio dos Sinos, Brasil

Gisela Castro I Escola Superior de Propaganda e Marketing, Brasil

Luciana Pellin Mielniczuk I Universidade Federal de Santa Maria, Brasi

Marcia Benetti I Universidade Federal do Rio Grande do Sul, Brasil

Paulo Cunha Carneiro Filho I Universidade Federal de Pernambuco, Brasil

Raquel Recuero I Universidade Católica de Pelotas, Brasil

REVISÃO DE TEXTO E TRADUÇÃO I Everton Cardoso

EDITORAÇÃO ELETRÔNICA I Raquel Castedo
COMPÓS I www.compos.org.br

Associação Nacional dos Programas de Pós-Graduação em Comunicação

Presidente

Itania Maria Mota Gomes

Universidade Federal da Bahia, Brasil

itania@ufba.br

Vice-presidente

Julio Pinto

Pontifícia Universidade Católica de Minas Gerais, Brasil

juliopinto@pucminas.br

Secretária-Geral

Ana Carolina Escosteguy

Pontifícia Universidade Católica do Rio Grande do Sul, Brasil

carolad@pucrs.br 